\title{
Smart Ambulance System with Remote Knowledge Communications Through Cloud
}

\author{
B. JAYASHREE ${ }^{\mathrm{a}, 1}$, A. SHIVARANJANI ${ }^{\mathrm{a}}$, S. SUVETHA ${ }^{\mathrm{a}}$, M. JANSI RANI ${ }^{\mathrm{b}}, \mathrm{P}$. \\ SURESHA BARANI ${ }^{\mathrm{b}}$ \\ ${ }^{a} U G$ Student, ${ }^{b}$ Assistant professor, Department of ECE, Panimalar Institute of \\ Technology, Chennai, India
}

\begin{abstract}
An ambulance is one of saving many lives by taking the people who need health emergencies. Saving the life of the person is one of the challenging and precious ones. Our key idea is to deliver a patient's health condition before the victim reaches the hospital in this project. Here we use some biomedical sensors like a heartbeat sensor, temperature sensor, and a respiratory sensor to check the patient health status. There will be a continuous update to the hospital about the patient's condition through the cloud with the help of the internet of things. The hospitals can also track the ambulance's live location through the GPS placed in the ambulance where it arrives, and they can know at what time the patient reaches the hospital. With this information, if the patient is in critical condition, the hospital staff can make all the earlier arrangements before the patient arrives at the hospital and saves their lives as soon as possible. Here we use the biometric sensor to know the patient's information by scanning the patient's fingerprint. The stored database obtains this information. In cases of accident situations, to avoid legal problems, the patient's information is sent to the cops through the GSM, and it is also intimated to the patient's relatives as soon as possible. The parameters which are measured by using biomedical sensors are viewed by doctors using the Blynk app.
\end{abstract}

Keywords. Biometric sensor, GPS, GSM, NODEMCU, Cloud server, Arduino UNO

\section{Introduction}

In India, an immense piece of metropolitan zone concocting brilliant Improving proficiency in the clinical advantages segment is a problematic undertaking which will require a portion of the authentic energy still, we can do it. We have made a thought out of bit-by-bit substance to make out a pointed recover vehicle with patient checking instrument concerning our endeavor [1]. We can see that dependably, and hour, somebody passes on considering not enduring proper treatment in an ideal manner. This problem can be eradicated by improving the efficiency of healthcare by transferring information from patient at rural health care unit to the doctor at other location through IoT for obtaining guidelines to undergo further treatment based on the patient data [5].

B.Jayashree, Department of ECE, Panimalar Institute of Technology, Chennai, India; Email: jayashreebabu2000@gmail.com. 
This paper notices the issue by stretching the odds of saving numerous people's existence by utilizing an arising headway in the Internet of Things, which is an accomplice for additional gadgets in essentially to the web. The idea of Internet of Things is a lot of accommodating to accomplish constant observing of sensor information [7]. IOT confirms our in general society more fruitful and helpful than we potentially envisioned whenever. Recently, clinical advantages structures have become a solid region and can be made rapidly by the clinical facility. The thriving status can be transported off to the emergency clinic. Android is an application that can be utilized by the clients by downloading android application [4]. So, we banded together with salvage vehicle but utilizing IOT to make it sharp crisis vehicle faraway data correspondence that can be gathered and give the persons flourishing status to the close by facility through the web which can view through Blynk application and the persons' information passes through SMS. GSM (SIM 800C), Arduino UNO (Atmega 328), GPS (NEO 6M) and NODE MCU (ESP8266) is used to achieve this, which accumulates essential information.

\section{Related Work}

A survey of this writing uncovers the progressing and expanded interest in IoT and IoT-based advances and arrangements [3]. An outline of the IoT is introduced. Despite the difficulties, like security, protection, Etc., that hinder IoT applications' advancement, the outline features the importance and advantages of the Internet of Things across different application spaces and regions [6].

Arita Baksi, Mayookh Bhattacharjee proposed a project in which each and every emergency vehicle, a GPS and GSM modem will be outfitted and at the emergency time GPS will send the fastest route from the vehicle's current location to the hospital through GSM [2].

\section{Proposed System}

The pictorial representation of proposed system is shown in Figure 1.

\subsection{Working Principle}

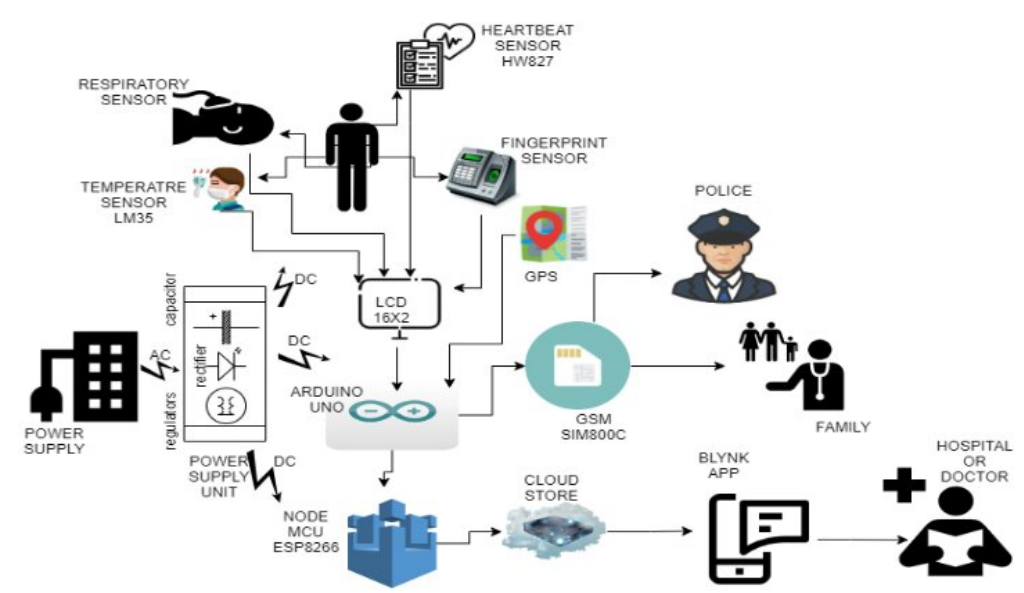

Figure 1. Pictorial representation of the project 


\subsection{Modules Description}

- Fingerprint Authentication: Biometric sensor module used in this project is R307. This alludes to the robotized strategy for checking a match between two human fingerprint [8].

- Heartbeat Sensor: HW827 is the heartbeat sensor used in this project which is measured by just placing the tip of your index finger delicately ludicrous all over.

- Respiratory Sensor: Treatment pressures must be observed and controlled in clinical instruments respiratory device.

- Node MCU: Node MCU ESP8266 is getting extraordinarily famous and are nearly utilized in more than half of IoT-based tasks today.

- GPS: GPS provides users with accurate information about their position and velocity. GPS used in this project is Neo 6M.

- GSM: In an SMT module highlighting an industry-standard interface, the SIM800CS is a quadband GSM/GPRS module that works on frequencies GSM850MHz.

- Temperature Sensor: The temperature sensor senses the patient body temperature. The LM35 operates over a temperature range of $-55^{\circ} \mathrm{C}$ to $150^{\circ} \mathrm{C}$.

\subsection{Projected Methodology}

Assuming this is the case, the courses of action for the treatment utilize the sensors that distinguish the boundaries like heartbeat rate, temperature, respiration, and so forth, connected to the Arduino. These sensors measure the values and send the live deals to the IoT. Those values will be updated in the cloud and ship off to the Hospital it is also personally viewed by the Blynk app by the doctors of the Hospital. Also, here we use GPS for live tracking of the Ambulance to monitor when the patient reaches the Hospital. Here our goal to execute an imaginative answer for this issue by building up a Person recognizable proof System utilizing biometric sensors. The result of all the sensors is displayed in LCD through the microcontroller and it sends the message to our mobile via GSM modem [6]. Ambulance offers assistance for an obscure individual who is confronting an accident or emergency and takes those individuals to the Hospital [9]. In this venture, I am adding some extra highlights inside the emergency vehicle to distinguish the individual confronting an accident or health emergency. After the recognizable proof is sent to Hospital and on the off chance that it is an accident case, the data is ship off close by the police station through the GSM module to stay away from lawful issues. It additionally diminishes the work weight to the police in distinguishing the subtleties of the individual. This framework has been created and carried out utilizing the unique biometric sensor-based embedded technology incorporated with the advancing Smart Device. It assists with offering the most astute support for the public smartly. The complete setup is projected in Figure 2. 


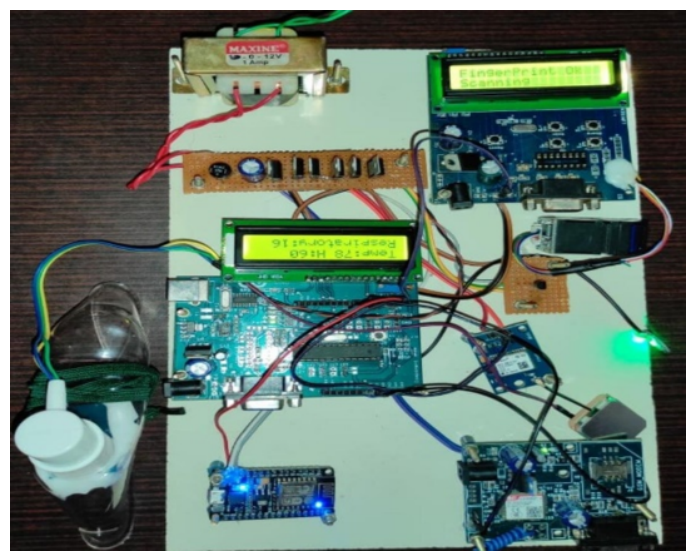

Figure 2. Complete hardware setup

\subsection{Flowchart}

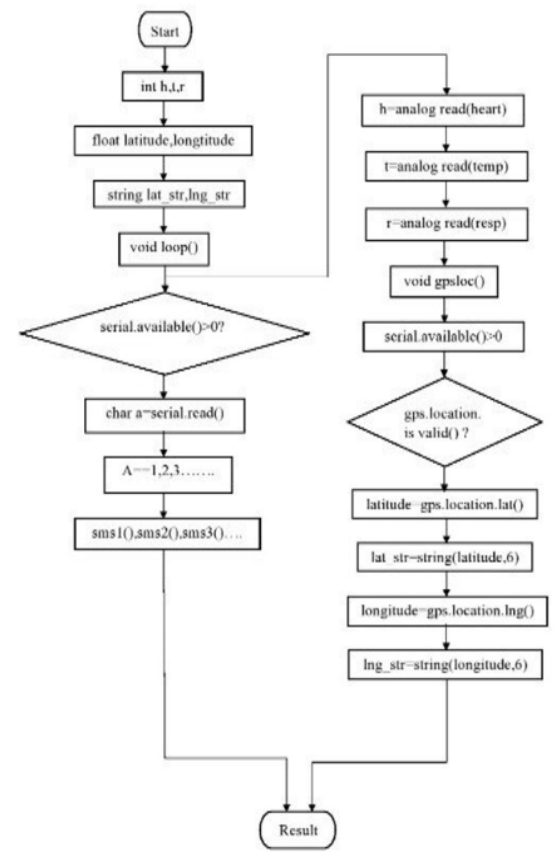

\section{Results and Discussion}

In this paper, we projected a patient checking framework inside the ambulance. We are utilizing some biomedical sensors. These sensors detect and send patients' conditions to the cloud through IoT, which can be constantly observed. Here, we associated the GPS 
tracker with following the ambulance's live area. The aftereffect of these can be seen in a solitary application by the specialists by Blynk application, which is appeared in Figure 3. Here we utilize a biometric sensor to recognize the patient data. An SMS is shipped off to the police/relatives through GSM, as demonstrated in Figure 4.

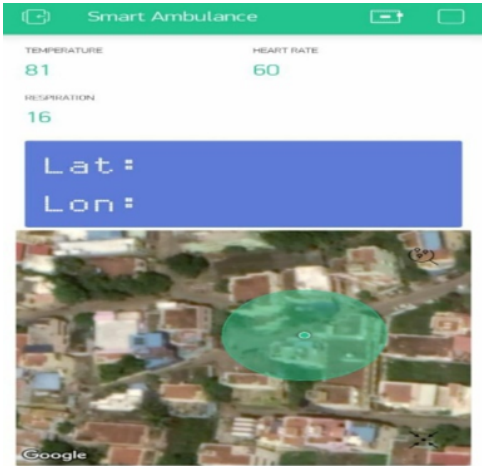

Figure 3. Result displayed in Blynk application

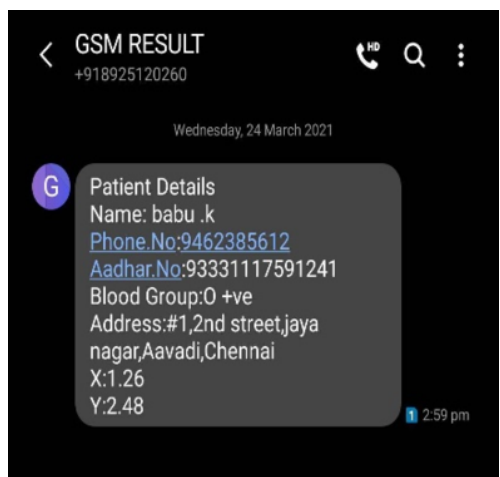

Figure 4. SMS received through GSM

\section{Conclusion}

This project keeps up its adaptability by protecting all information in a solid IoT in CLOUD. The information moved through an IOT CLOUD is guaranteed to be confidential and secure. The graphical portrayal acquired in the approved web worker that speaks with IoT cloud is accurate and exact. Henceforth, directing the vehicle through a worker-decided way will save precious, meaningful time for the patient, bringing about diminished odds of mortality just as a considerable decline accordingly the paramedics' response time.

\section{References}

[1] Divya D. Nanwani, Puja R. Kshirsagar, Bhavana P. Kawal Kar, Pritish Deshmukh "Ambulance Tracking and Patient Health Monitoring Using GPS and GSM" International Journal of Emerging Technologies in Engineering Research (IJETER) Volume 5, Issue 3, March (2017), ISSN: 2454-6410.

[2] Baksi, A., Bhattacharjee, M., Ghosh, S., Bishnu, S. K., \& Chakraborty, A. (2020). Internet of Things (IOT) Based Ambulance Tracking System Using GPS and GSM Modules. In 2020 4th International Conference on Electronics, Materials Engineering and Nano-Technology, IEMENTech 2020. Institute of Electrical and Electronics Engineers Inc. https://doi.org/10.1109/IEMENTech51367.2020.9270120

[3] Bhagchandani, K., \& Peter Augustine, D. (2019). IoT based heart monitoring and alerting system with cloud computing and managing the traffic for an ambulance in India. International Journal of Electrical and Computer Engineering, 9(6), 5068-5074. https://doi.org/10.11591/ijece.v9i6.pp5068-5074

[4] V.Baarathi, T.Balaji, A.T.Navin Prasad, M.Jansi Rani "Offline SMS Internet" , International Research Journal of Engineering and Technology (IRJET), Vol.No.4, Issue No.3, PP. 2376-2378, March 2017, ISSN:2395-0056.

[5] G.K.Srinandhala J.Navarajan, S.Manoj, R.Saravanan, "Remote Patient Monitoring Using Internet of Things" International Journal of Advanced Research Methodology in Engineering \& Technology, Volume 1,Issue 3,Pages 14-16, May 2017.

[6] M.Jansi Rani, Jahan.J, Anitha.D, Hennah Florida.V "Intelligent Farm House Automation Using Green House Method and Plant Image Processing Using MATLAB”, International Journal of Advanced 
Research in Electrical, Electronics and Instrumentation Engineering(An ISO 3297: 2007 Certified Organization)Vol. 5, Issue 3, March 2016.

[7] J.Navarajan, B. Aswin kumar, S. venkatesh, T. Jayachandran "Detection of Water Pollution and Water Management Using Smart Sensors with IOT", International Research Journal of Engineering and Technology (IRJET) e-ISSN: 2395 -0056 Volume: 04 Issue: 04 | Apr -2017.

[8] C. Jain, G. V. S. Sashank, V. N and S. Markkandan, "Low-cost BLE based Indoor Localization using RSSI Fingerprinting and Machine Learning," Sixth International Conference on Wireless Communications, Signal Processing and Networking (WiSPNET), 2021, pp. 363-367, https://doi.org/10.1109/WiSPNET51692.2021.9419388

[9] C. C., G. B. R., S. M., A. M., B. R. and M. Balaji, "Machine Learning Based Condition Recognition System for Bikers," 2020 7th International Conference on Smart Structures and Systems (ICSSS), 2020, pp. 1-6, 10.1109/ICSSS49621.2020.9202245 